\title{
USO DE BIG DATA NA FORMULAÇÃO LEGISLATIVA
}

\author{
USE OF BIG DATA IN LEGISLATIVE FORMULATION
}

\author{
MARio Luiz RAMidofF ${ }^{1}$ \\ FERNANDA GONÇALES ${ }^{2}$ \\ GREGório MENZEL ${ }^{3}$
}

\begin{abstract}
RESUMO
A utilização de dados no desenvolvimento de produtos e serviços mais eficientes para o mercado consumidor não é novidade. Mas em se tratando de produção normativa, seria possível o uso de big data para a elaboração de leis mais assertivas tornando-as mais eficazes? O texto pretende explorar, sob o viés da análise econômica do direito, como o legislativo pode se beneficiar do uso da Inteligência Artificial na produção normativa. De um lado, leis mais inteligentes podem servir o cidadão de forma mais rápida e eficaz; de outro lado, podem ajudar o Estado a melhorar suas ineficiências com significativa redução de custos. Como resultado, o texto pretende fomentar o debate sobre o uso de dados, os limites de sua exploração e as vantagens para o processo de criação normativa.
\end{abstract}

PALAVRAS-CHAVE: big data; governança de dados; leis eficientes; eficientismo.

\begin{abstract}
The use of data in the development of more efficient products and services for the consumer market is nothing new. But, if you are dealing with normative production, would it be possible to use big data to create more assertive laws, making them more effective? The text intends to explore, under the bias of the economic analysis of law, how the legislature can benefit from the use of Artificial Intelligence in normative production. On the one hand, smarter laws can serve citizens more quickly and effectively, on the other hand, they can help the State improve its inefficiencies with reduced cost savings. As a result, the text intends to foster a debate about the use of data, the limits of its exploitation and its advantages for the normative creation process.
\end{abstract}

KEYWORDS: big data; data governance; efficient laws; efficiency

\footnotetext{
${ }^{1}$ Desembargador no Tribunal de Justiça do Estado do Paraná; Mestre (PPGD- UFSC) e Doutor em Direito (PPGDUFPR); Estágio Pós-Doutoral (PPGD-UFSC); Professor Titular no Centro Universitário Curitiba (Graduação) e Professor Colaborador no PPGD-UNICURITIBA (Mestrado/Doutorado).

${ }^{2}$ Advogada. Mestranda em Direito no Programa de Pós-Graduação Strictu Sensu da UNINTER, com bolsa 100\%, na linha de pesquisa Jurisdição e Processo na Contemporaneidade. Pós-graduada em Direito Processual Civil pela Academia Brasileira de Direito Constitucional - ABDCONST.

${ }^{3}$ Mestrando em Direito Empresarial e Cidadania pelo Centro Universitário Curitiba - UNICURITIBA. Pesquisador do Grupo de Pesquisa Cidadania Empresarial no Século XXI registrado no CNPq.
} 


\section{INTRODUÇÃO}

Big data se tornou um recurso importante no desenvolvimento e aprimoramento de produtos.

Como exemplo; um banco pode utilizar dados sobre o hábito de navegação dos usuários em seu site para aprimorar a visualização da tela do programa e melhorar a experiência do cliente, com a redução de tempo entre o usuário logar ${ }^{4}$ no site e efetivar um pagamento.

O uso de "dados comportamentais" também é utilizado para o marketing direcionado. Diversos outros serviços utilizam da mesma técnica, catalogando o comportamento do usuário para, a partir daí, direcionar uma publicidade condizente ao seu perfil inferido. O usuário da rede é, portanto, a todo momento monitorado, acumulando-se uma série de dados (comportamentais), que são aplicados para a personalização da abordagem publicitária. (BIONI, 2018. p. 20)

Outros modos do uso de big data podem ser apontados; fabricantes de automóveis podem usar dados em tempo real sobre os hábitos de direção dos motoristas para aprender como seus carros respondem a diferentes padrões de direção.

Se compartilhados com o governo, os mesmos dados poderiam ser usados para definição de limite de velocidade de acordo com o estado de conservação da pista ou de acordo com a finalidade de uso de cada veículo ${ }^{5}$, ou ainda, para aplicação de multas em caso de desrespeito às normas de trânsito.

No caso da aplicação, o Estado sequer teria o custo da instalação de monitores de velocidade, uma vez que o próprio veículo traria essa informação o que pode representar uma vantagem significativa para o poder público.

Em contrapartida, para o cidadão a segurança no trânsito seria o benefício mais imediato.

Como nem tudo são flores na era tecnológica, a coleta de dados, seja pelo próprio governo ou por meio de compartilhamento da iniciativa privada, para fins de elaboração e

\footnotetext{
${ }^{4}$ Verbo adaptado do conceito de "fazer login". Login é o início de uma sessão de conexão em que geralmente é feita a identificação do usuário no sistema.

${ }^{5}$ No Brasil, ainda que já exista diferenciação de limites de velocidade com base nos modelos padrões (ônibus, caminhões e veículos pequenos) cargas vivas ou de alimentos perecíveis poderiam ter um limite de velocidade diferente dos demais tipos de cargas.
} 
aplicação da lei, levanta preocupações óbvias por conta de dois preceitos fundamentais previstos na nossa Constituição; o direito à liberdade e o direito à privacidade.

Nas últimas décadas muito se discute sobre as vantagens do uso de dados para a melhoria da vida de consumo em geral, mas quando se trata da intervenção do Estado é preciso muita cautela, para que o uso de informações obtidas através da coleta de dados - e destacadamente pela maneira em que se dá essa coleta de dados - não se torne uma ameaça às liberdades públicas (civis) tão penosamente conquistadas no decorrer dos anos e da evolução da civilizatória.

A utilização de big data pelo Estado é um caminho inevitável, mas é necessário fomentar a discussão sobre os seus limites, como, por exemplo, acerca da transparência, do consentimento e do direito de oposição a ser garantido ao cidadão.

Este texto pretende fomentar a discussão do tema a partir da análise dos conceitos de inteligência artificial e de big data, bem como de que maneira a inciativa privada pode se beneficiar desses novos instrumentos.

Em seguida, propõe-se debater como o Estado poderia utilizar a inteligência artificial e os dados coletados para tornar as leis mais eficazes/eficientes com significativa redução de custos e melhoria de processos administrativos.

Apesar de não ser o ponto principal do trabalho, é necessário apontar os riscos do uso inadequado de dados tecnologicamente coletados e da utilização da inteligência artificial, notadamente quando se trata de direitos e garantias fundamentais do cidadão, enquanto limites constitucionais de toda e qualquer espécie de intervenção estatal.

Nem é preciso lembrar acerca da importância da cautela na utilização da legislação apenas como um meio de se atingir a eficiência econômica, pois, como se sabe, o essencial é criar soluções que gerem o menor custo-benefício, sobretudo em matéria de políticas públicas, e, que, assim, ao mesmo tempo tragam efetivos benefícios a administrados; como, por exemplo, a segurança e a rapidez.

Portanto, um maior diálogo entre os raciocínios jurídico, econômico e tecnológico ${ }^{6}$, reconhecendo as limitações destes ramos do conhecimento para a descrição da realidade,

\footnotetext{
${ }^{6} \mathrm{O}$ raciocínio jurídico e a boa dogmática jurídica não são surdos aos saberes alheios e se dão conta de que vários objetos constituídos por outras disciplinas são a matéria prima sobre a qual decidem. Embora decidindo segundo regras, o jurista sabe que o objeto de sua decisão, o caso sobre o qual ele quer aplicar as regras, não são regras mesmas, mas as relações entre pessoas e estas são explicadas e constituídas por muitos saberes que não apenas o direito (LOPES).
} 
poderá contribuir sobremaneira para uma melhor compreensão, interpretação e elaboração de mecanismo mais eficientes para o Estado, sem deixar de lado os direitos fundamentais de seus cidadãos.

\section{INTELIGÊNCIA ARTIFICIAL E BIG DATA}

Para estabelecer a relação entre os temas abordados neste texto é importante não só conceituar, mas, sim, conceituar de forma contextualizada (datada) as expressões "Inteligência Artificial" e "Big Data".

No século XIX, Allan Turing ${ }^{7}$ sustentava que "é inteligente uma máquina que é capaz de iludir e passar por inteligente aos olhos dos homens".

Ele propôs a construção de máquinas "inteligentes", que fossem capazes de imitar comportamentos humanos, ou seja, agissem com intencionalidade.

Segundo Pozzebon, Frigo e Bittencourt (2004) o desenvolvimento da Inteligência Artificial sempre esteve diretamente ligado à evolução dos computadores.

Através das máquinas foi possível simular aspectos da inteligência humana, questionando-se se as máquinas seriam inteligentes, tal como os seres humanos, e capazes de aprender.

A Inteligência Artificial foi reconhecida como ciência no ano de 1956.

Contudo, até o momento não existe uma definição suficientemente satisfatória do próprio termo inteligência e, para se compreenderem os processos da inteligência artificial e da representação do conhecimento, é necessário dominar os conceitos de inteligência humana e conhecimento.

O que se pode apontar é que a Inteligência Artificial é, tanto, uma ciência que procura estudar e compreender o fenômeno da inteligência, quanto, uma área da engenharia que procura construir instrumentos para apoiar a inteligência humana (POZZEBON; et al, 2004).

Corvalón (2017) sintetiza IA como estratégias de programação e de máquinas físicas para reproduzir tarefas cognitivas e técnico científicas denominadas de inteligentes.

Para o Autor:

\footnotetext{
7 Alan Mathison Turing (1912-1954), matemático britânico, pioneiro da computação é considerado o pai da ciência computacional e da inteligência artificial. Fonte: https://www.ebiografia.com/alan_turing/.
} 
La IA desarrolla ciertos procesos de forma autónoma, muchas veces sin imitar o simular el proceso que se desarrolla en el cerebro humano, pero obteniendo iguales o mejores resultados en ciertos campos o áreas de conocimiento. Por ejemplo, Google no necesita saber la estructura gramatical de los diferentes idiomas para realizar traducciones medianamente razonables, que al menos suponen una comprensión básica de información escrita en otro idioma. Aprende de los patrones que extrae de la información y los datos. Por tanto, podemos afirmar que hay varios caminos no excluyentes entre sí por los cuales la IA iguala, mejora, potencia y/o maximiza los resultados de muchas actividades humanas inteligentes, a través de la optimización continua y exponencial del procesamiento de información ${ }^{8}$.

Russel e Norvig (2004, p. 5) definem Inteligência Artificial a partir da classificação de processos de pensamento ou comportamento, considerando a similaridade com relação ao ser humano ou a alguma racionalidade envolvida.

Nesse sentido, quando se fala de um software inteligente que envolva tomada de decisões, estaria implícita a definição sobre "pensar como o ser humano"9. Em termos mais simples, a Inteligência Artificial seria a capacidade de mecanismos artificiais (máquinas, programas) possuírem comportamento inteligente, racionar e agir como o homem.

O desenvolvimento de soluções baseadas na Inteligência Artificial facilita nosso dia a dia, quase todos os habitantes do planeta Terra são donos de pelo menos um celular, grande parte da população desenvolve seu trabalho com o uso de ferramentas tecnológicas, do mesmo modo a maioria dos governos já faz uso de algum mecanismo baseado em tecnologia para identificação de seus cidadãos e armazenamento de dados.

O uso dessas tecnologias gera informações de forma contínua em uma velocidade sem precedentes. Cada vez mais as organizações, públicas e privadas, estão produzindo grandes quantidades de dados provenientes de diferentes fontes. Contudo, a simples existência dessas informações, não é de grande utilidade, ou seja, os dados precisam estar armazenados e organizados de modo que possam ser processados para agregar-lhes valor.

Vianna, Dutra e Frazzon (2016, p.193), enfatizam a importância da gestão efetiva e

\footnotetext{
${ }^{8}$ A IA desenvolve certos processos de forma autônoma, geralmente sem imitar ou simular o processo que ocorre no cérebro humano, mas obtendo os mesmos ou melhores resultados em determinados campos ou áreas do conhecimento. Por exemplo, o Google não precisa conhecer a estrutura gramatical de diferentes idiomas para realizar traduções razoáveis, o que supõe pelo menos um entendimento básico das informações escritas em outro idioma. Aprende com os padrões que extrai de informações e dados. Portanto, podemos afirmar que existem vários caminhos, não excludentes entre si, pelas quais a IA iguala, melhora, aprimora e/ou maximiza os resultados de muitas atividades humanas inteligentes, por meio da otimização contínua e exponencial do processamento de informações. Tradução livre.

${ }^{9}$ O computador Deep Blue, desenvolvido pela IBM na década de 1990, tornou-se famoso por vencer o campeão mundial de xadrez Garry Kasparov.
} 
da necessidade de transformar esses dados em informações de qualidade, para possam ser utilizadas no direcionamento de negócios e de estratégias das organizações, minimizando riscos, e apoiando o processo de tomada de decisões.

As redes sociais, por exemplo, demandam o gerenciamento de grandes quantidades de dados não estruturados ${ }^{10}$, gerados diariamente por milhões de usuários em busca do compartilhamento de informações, conhecimentos e interesses (LÓSCIO, 2011).

É justamente aqui que surge a importância da análise desses dados. Mas o que significa na prática o termo big data?

O termo big data é um conceito abstrato que surgiu em meados de 2010 para designar a tendência tecnológica de gerar grandes quantidades de dados, de diferentes origens e formatos (CHEN; et al., 2014).

O guia da TechAmerica Foundation (2012, p. 9) define big data como:

Big Data is not a technology, but rather a phenomenon resulting from the vast amount of raw information generated across society, and collected by commercial and government organizations. This phenomenon represents both a challenge in harnessing this volume of data, and an opportunity for government agencies who seek to enhance their effectiveness ${ }^{11}$.

Para Erl, Khattak e Buhler (2016), big data é um campo que se dedica à análise, ao processamento e armazenamento de grandes dados relacionados ente si, e utilizado quando as tecnologias e técnicas tradicionais disponíveis não são suficientes para a execução destas atividades.

Para Manyika (2011), big data é derivado do fato de que os conjuntos de dados são tão grandes que os sistemas de banco de dados comuns não têm capacidade para armazenálos, tampouco analisá-los.

São chamados de grandes (big) porque os dados não são estruturados (não tem uma

10 Dados estruturados são aqueles organizados e representados com uma estrutura rígida, a qual foi previamente planejada para armazená-los. Qual é o oposto de uma estrutura rígida e previamente pensada? Uma estrutura flexível e dinâmica ou sem estrutura. Exemplo mais comum? Um documento ou um arquivo. Assim, é fácil concluir que as redes sociais, as quais possuem um enorme volume de dados, como textos, imagens e vídeos criados diariamente por usuários, representam outro exemplo de dados não estruturados. Atualmente, mais de $80 \%$ do conteúdo digital gerado no mundo é do tipo não estruturado. Texto adaptado. Fonte: https://universidadedatecnologia.com.br/dadosestruturados-e-nao-estruturados/.

${ }^{11}$ Big Data não é uma tecnologia, mas um fenômeno resultante da grande quantidade de informações brutas geradas em toda a sociedade e coletadas por organizações comerciais e governamentais. Esse fenômeno representa um desafio para aproveitar o volume de dados e uma oportunidade para agências governamentais que buscam melhorar sua eficácia. Tradução livre. 
organização), vez oriundos novas fontes, incluindo e-mail, mídias sociais e sensores acessíveis pela Internet.

Pode-se dizer que termo big data caracteriza a operação de coleta, armazenamento, organização, para análise, obtenção de conclusões, captação de padrões, vínculos, comportamentos e tendências, a partir de um grande volume de informações.

Dados também podem ser usados para criar um “perfil digital” de cada usuário, para criar produtos e serviços personalizados.

Por exemplo, um site de notícias capta todo o comportamento do usuário na sua página, (cliques, notícias mais acessadas, tempo de navegação, localização do usuário, etc), a partir do resultado da análise dos dados pode direcionar ao leitor matérias e publicidade, segmentada, que sejam de seu interesse.

\section{SoluÇões Com Base em Algoritmos}

O crescimento do tráfego de dados nos países emergentes ultrapassa os $100 \%$ ao ano.

A análise dessas informações pode apontar necessidades e esclarecer comportamentos dos cidadãos de um determinado país, ou residentes de uma região específica.

A construção de soluções centradas nos usuários pode possibilitar melhor acesso aos serviços de saúde, transporte, educação, serviços financeiros e agricultura notadamente para regiões de baixo desenvolvimento (WEF, 2012).

Novos produtos e serviços pensados e desenvolvidos com base em algoritmos estão presentes no nosso dia a dia há bastante tempo.

Por exemplo, semáforos inteligentes que usam padrões do trânsito, clima, hora do dia, proximidade de outros veículos etc., para personalizar as diretrizes de tráfego.

Para o motorista, a tecnologia converte todas essas informações na forma simples de uma luz verde ou vermelha.

\subsection{SERVIÇOS FINANCEIROS}


Os dados captados de serviços financeiros podem fornecer uma leitura do hábito de consumo, pagamento e histórico de endividamento dos moradores de determinada região. Com base no histórico financeiro, o cidadão, pequeno empresário ou agricultor pode ser candidato à tomada de empréstimos com juros mais baixos. (WEF, 2012).

\subsection{EDUCAÇÃO}

Através do monitoramento do comportamento de alunos em atividades e aulas on-line, é possível determinar a melhor abordagem para cada conteúdo a ser lecionado (TECHAMERICA, 2012).

A educação, com uso da análise de dados, pode sofrer grandes mudanças, passando a ser direcionada conforme as características do aluno para desenvolvimento de suas habilidades. Inclusive pode-se considerar o acompanhamento integral de sua evolução acadêmica para fins de concessão de bolsas de estudos para aqueles que detiverem os melhores desempenhos.

Algoritmos também são usados para analisar comportamento e consumo, Netflix, Spotify e Youtube utilizam desse mecanismo para sugerir aos usuários conteúdo com base em seus interesses.

\subsection{SERVIÇOS DE SAÚDE}

Em se tratando da área de saúde, o uso de big data pode fazer uso de sensores no paciente enquanto estiver no hospital ou mesmo em casa para manter monitoramento continuo dos principais marcadores bioquímicos, realizando a análise em tempo real dos dados.

No cotidiano o sistema de análise pode alertar individualmente cada pessoa e o respectivo médico, exigindo uma visita ao mesmo ou até mesmo alertando o "911" de um evento que estará prestes a acontecer.

Este serviço pode ampliar e melhorar a qualidade de vida de muitas de pessoas (TECHAMERICA, 2012).

Neste ponto, considerando que o aumento populacional de pessoas em idade 
avançada o uso da tecnologia de dados pode trazer a possibilidade de um atendimento mais rápido e assertivo em momentos de emergência.

\subsection{AgRICULTURA}

A análise de compras de insumos agrícolas pode auxiliar na projeção da produção, para fins de monitoramento de estoques e precificação.

Esse conhecimento pode ser usado para reduzir resíduos e desperdício, possibilitando a melhoria das informações sobre quais tipos de serviços financeiros são necessários para os agricultores.

Desvios de comportamentos, em regiões afetadas por catástrofes naturais por exemplo, também podem ajudar os governos e organizações a identificar produtores em dificuldade, de modo que a assistência possa ser direcionada a eles.

A detecção antecipada pode ajudar a evitar que as famílias deixem suas terras diminuindo ainda mais a produção agrícola (WEF, 2012).

Esses são alguns exemplos sobre como o uso de algoritmos pode auxiliar o poder público na tomada de decisões efetivas, economizando recursos e desenvolvendo soluções estratégicas, considerando além dos dados atuais, as projeções futuras como média de vida da população, recursos naturais, taxa de urbanização, entre outras.

O Estado por si já dispõe de um número incontável de informações de seus cidadãos, relacionadas a saúde, educação, fiscal, vida pregressa entre outras.

O poder público ao desenvolver suas atividades também produz muito material que pode ser utilizado, receitas, despesas e orçamentos.

Empresas privadas também compartilham dados com o poder público, o que torna as fontes disponíveis bem variadas.

Diversas políticas públicas podem ser adotadas e melhoradas para facilitar a mobilidade urbana, definir os melhores locais para instalação de parques industriais, aprimorar o sistema de saúde e combate de endemias, ou seja, uma gama enorme de possibilidades. 


\section{Efetividade NoRmativa PELo Ecossistema digital}

No sistema de economia digital, os dados são importante impulsionador da inovação, em termos de bem-estar social há uma infinidade de áreas que podem se beneficiar desse ecossistema.

Dentro dessa realidade, considerando todas as discussões sobre efetividade e eficácia das normas e suas implicações na ordem econômica, porque não pensar em leis criadas a partir da análise de dados.

ELKIN-KOREN e GAL (2018), utilizam o termo personalized law para nomear leis desenvolvidas a partir da análise de dados.

Para fins de criação de leis com base na dinâmica da coleta de dados, fontes distintas podem ser necessárias: informações coletadas pelo governo e coletados por empresas privadas.

Os autores demonstram este ponto por meio da ilustração abaixo;

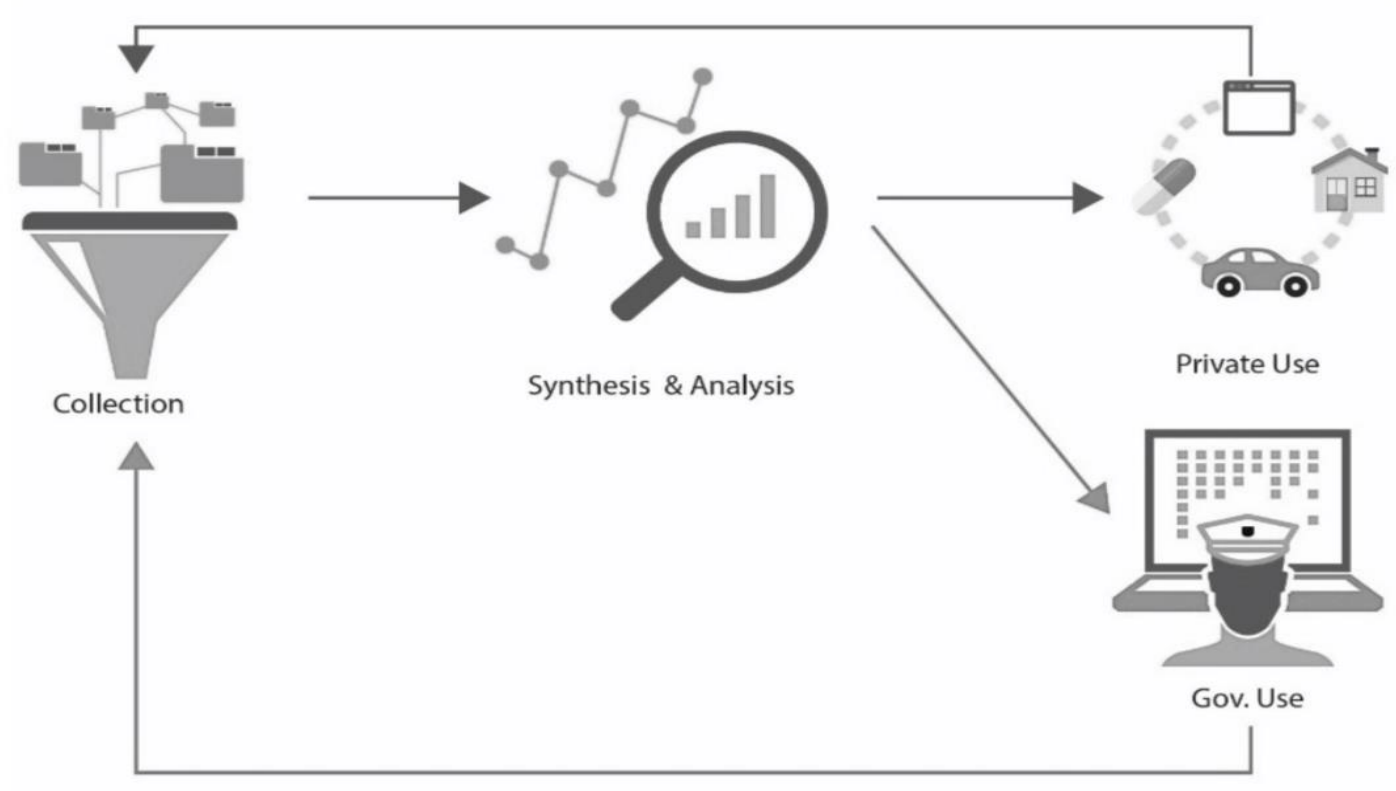

A imagem descreve o ciclo da coleta e uso de informações; coletadas pelo governo e inciativa privada, organizadas e analisadas e disponibilizadas para uso. 
Vale apontar que apesar da origem de coleta distintas os dados oriundos das duas fontes não se sobrepõem.

Por exemplo, o governo coleta dados de câmeras de controle de tráfego, censos e órgãos de trânsito.

Alguns desses dados podem ser únicos e outros semelhantes aos coletados por empresas privadas, como seguradoras.

Os dados coletados pelo governo nem sempre são suficientes para elaborar leis personalizadas.

Nesses casos, o governo pode investir recursos na coleta desses dados ou optar por adquirir dados coletados por empresas privadas. Atualmente a comunicação digital, a coleta e o armazenamento de dados são atualmente dominados por empresas privadas.

Em alguns casos, pode ser necessária uma combinação de dados de fontes governamentais e privadas (ELKIN-KOREN; GAL 2018).

A qualidade dos dados é um dos fatores mais importantes, na medida em que serão a base de sustentação de toda a análise e posterior desenho da lei.

\begin{abstract}
The question of whether an algorithm can achieve the objective of the law turns on the quality of the data that a lawmaker relies on. The concern here is whether the data actually measure the relevant factors and adequately predict the central objective of the law. This raises obvious procedural issues. How much relevant data are available? Who collected the data - are they impartial, and what biases do they bring? How and why did they collect the data? What potential biases are lurking in the data, and can those biases be corrected? CASEY e NIBLETT $\left(2019\right.$, p. 349-350) ${ }^{12}$
\end{abstract}

A ideia de que a lei deve ser adaptada para melhor se adequar ao contexto relevante ao qual se aplica é óbvia e existe desde a própria ideia de lei.

De fato, toda lei tem alguns parâmetros contextuais.

A questão é quão específicos - ou quão finamente adaptados - serão esses parâmetros.

\footnotetext{
${ }^{12}$ A questão de saber se um algoritmo pode atingir o objetivo da lei se baseia na qualidade dos dados em que um legislador se baseia. A preocupação aqui é se os dados realmente medem os fatores relevantes e preveem adequadamente o objetivo central da lei. Isso levanta questões processuais óbvias. Quantos dados relevantes estão disponíveis? Quem coletou os dados - eles são imparciais e que preconceitos eles trazem? Como e por que eles coletaram os dados? Que tendências potenciais estão ocultas nos dados e essas tendências podem ser corrigidas? Tradução livre.
} 
Em um mundo sem atritos, uma lei ideal levaria em consideração todos os fatores contextuais relevantes - e não irrelevantes (CASEY; NIBLETT, 2019).

As Leis possuem um custo - político, social, econômico, financeiro, dentre outros - muito alto para serem criadas (formulação legislativa) e aplicadas (dotações orçamentárias), mas com o avanço tecnológico, os parâmetros podem ser definidos a partir da análise de informações, direcionando o legislador a elaborar a lei com objetivos mais claros, o que facilita a posterior aplicação da lei, inclusive.

Por certo, que, uma outra questão fundamental se propõe, agora, acerca do custo tecnológico a ser agregado aqueles anteriores fatores de dificuldade na formulação legislativa habitual.

CASEY e NIBLETT (2019, p. 343-344), apontam indicadores que podem auxiliar o legislador na tarefa de desenvolver com base em dados.

A partir de parâmetros colhidos da jurisprudência, os algoritmos podem ser usados para mapear o comportamento judicial e prever como os juízes decidem casos semelhantes.

O algoritmo procura encontrar padrões ocultos nos dados para entender o posicionamento dos juízes.

Com base nessa análise, melhorar a lei, principalmente reduzindo a inconsistência das decisões judiciais e minimizando a probabilidade de decisões discrepantes e, ao mesmo tempo, permitindo que a lei leve em consideração os fatores pessoais dos indivíduos.

Assim, o uso do algoritmo como base para a lei proporciona aos cidadãos maior certeza e consistência.

Para os supramencionados Autores, seria possível dizer que "there are fewer cases litigated in a world in which outcomes can be predicted"13.

O uso de algoritmos no processo de elaboração de leis não afasta a necessidade de participação do componente humano, embora possam reduzir erros, algoritmos não podem erradicá-los completamente.

Os algoritmos fornecem aos tomadores de decisão humanos mais informações sobre o contexto da decisão, simplificando o processo.

\footnotetext{
${ }^{13}$ Há menos casos litigados em um mundo em que os resultados podem ser previstos. Tradução livre.
} 
Para desenvolver a lei, o legislador precisa de informações granulares sobre indivíduos e grupos.

Até recentemente, a vigilância em larga escala e o processamento de dados pareciam tecnologicamente inviáveis.

No entanto, as tendências de coleta e análise de informações sugerem que o legislador terá capacidade técnica de vincular diretrizes a traços individuais altamente específicos.

\title{
4. Desafios da Regulamentação baseada na InteligênCia Artificial e em dados
}

Uma outra questão que se encontra posta, na contemporaneidade, a discussão, é a regulamentação do uso da inteligência artificial, vale dizer, os desafios normativos e tecnológicos para a formulação legislativa de regras que se destinem a disciplinar a utilização de dados e informações veiculados em uma base computacional-eletrônica; senão, para a própria regulamentação do marco legal da inteligência artificial, por exemplo.

Leis criadas com base no uso de algoritmos buscam procura tirar proveito das vantagens tecnológicas, principalmente, para coleta e ciência de dados que permitam que os dados sejam transferidos, armazenados, organizados e analisados de maneira eficiente, a fim de padronizar normas legais, efetivando direitos e reduzindo custos para o Estado.

Nesse processo alguns desafios podem ser apontados.

Corvalán (2017) destaca que a preocupação primordial no uso de dados pelo Estado deve ser a efetividade dos direitos humanos, in verbis:

\begin{abstract}
Encuadrar a la IA en el marco del Estado constitucional presupone enfocar su diseño, desarrollo y uso a partir de respetar la dignidad humana y los derechos humanos. Se trata, básicamente, de hacer más robusto el sistema de protección a partir de incorporar al bloque de juridicidad una serie de principios generales tendientes a regularla ${ }^{14}$.
\end{abstract}

Certamente compatibilizar a IA com os direitos humanos é um desafio complexo e

\footnotetext{
${ }^{14}$ Enquadrar a IA com status constitucional pressupõe focar seu design, desenvolvimento e uso com base no respeito à dignidade e aos direitos humanos. Basicamente, trata-se de tornar o sistema de proteção mais robusto, incorporando uma série de princípios gerais para regulamentá-lo no sistema jurídico. Tradução livre.
} 
indispensável nos próximos anos.

Há outros pontos que merecem destaque nessa discussão; a transparência, a nãodiscriminação e o consentimento.

Em se tratando da coleta de dados pelo poder público, para que o cidadão possa compreender a razão do uso de suas informações, se faz necessário transparência por parte do poder Estatal sobre a realização de tratamento de dados.

Para a administração pública brasileira a transparência é requisito obrigatório, muito mais do que apresentar informações, é necessária a transparência ativa, traduzida na disponibilização, de maneira aberta e antecipada, o livre acesso, inclusive e especialmente pela internet, dos dados relacionados às atividades do Estado.

Nesse contexto, a inteligência artificial deve ser "transparente" em suas decisões, o que significa que uma "explicação compreensível” pode ser inferida ou deduzida sobre os critérios utilizados para chegar àquela determinada conclusão, sugestão ou resultado $\mathrm{O}$ design, desenvolvimento e uso da IA devem ser transparentes e abertos.

A transparência algorítmica está ligada à proibição da existência de "caixas pretas" nos algoritmos ou à existência de medidas contra danos ou ferimentos que eles possam causar. (CORVALÁN, 2017).

A lei, em tese, trata todos de forma igual.

Do mesmo modo, o uso de algoritmos deve respeitar o princípio da não discriminação, significa impedir que máquinas - baseadas em sistemas de IA - processem informações ou dados sob vieses ou distinções, com base em raça, cor, sexo, idioma, religião, opinião política ou outra, origem nacional ou social, posição econômica, nascimento ou qualquer outra condição social. (CORVALÁN, 2017).

Como o Estado vai tratar a questão do consentimento é outro ponto que merece debate.

O uso privado de dados depende do consentimento e enfrenta limitações.

O consentimento deve ser significativo, e não o resultado de erro ou coação.

Além disso, alguns direitos não podem ser renunciados por contrato ou acordo.

Para Verstein (2019), o direito público assegura sua legitimidade não através do consentimento real, mas através de algum fundamento explicável na filosofia política; 
While the details of this foundation may be contested, we usually hold state action to political, procedural, and substantive standards. Politically, the current practices of the state must be traceable to current politics in a way that grounds law in the will of its subjects. Procedurally, states must regularize their use of power. For example, certain rights may be compromised but only by law enforcement officials after a suitable trial. Substantively, states are constrained by their constitutions and perhaps other features of justice to protect certain rights and interests ${ }^{15}$.

Feigelson (2019, p. 80) lembra que o consentimento é a base para julgar se determinado uso de dados pessoais é legítimo, além de ser um instrumento para restringir a transferência de dados a terceiros.

O Autor aponta que o consentimento deve ser manifestado por quem detenha entendimento substancial acerca das consequências da sua manifestação de vontade.

\section{CONSIDERAÇÕES FINAIS}

O uso de novas tecnologias e da Inteligência Artificial é um ponto que não pode ser ignorado pelo Estado.

Estamos na era de ouro da coleta e análise de dados, o número de dispositivos que registram informações sobre nossas ações, hábitos e consumo estão crescendo exponencialmente, assim como o volume de dados coletados, organizados, sintetizados, analisados, armazenados e usados por entidades privadas.

O Estado precisa reconhecer o potencial que as informações têm para melhorar sua infraestrutura e reduzir despesas.

Os avanços na inovação orientada a dados, oferecem novas oportunidades não apenas para o setor privado, mas também para o público.

O uso da IA poderia fortalecer a aplicação da lei e torná-la mais eficiente.

De todo modo, o uso de novas tecnologias não pode sobrepor-se aos direitos

\footnotetext{
${ }^{15}$ Embora os detalhes dessa base possam ser contestados, em geral mantemos a ação estatal de acordo com padrões políticos, processuais e substantivos. Politicamente, as práticas atuais do Estado devem ser rastreáveis à política atual, de maneira a fundamentar a lei na vontade de seus súditos. Processualmente, os estados devem regularizar o uso do poder. Por exemplo, certos direitos podem ser comprometidos, mas apenas pelos agentes da lei após um julgamento adequado. Substancialmente, os estados são obrigados por suas constituições e talvez outras características da justiça para proteger certos direitos e interesses. Tradução livre.
} 
fundamentais do cidadão.

Ao se pensar no desenvolvimento de leis com uso de IA, a estratégia possível é lançar um programa piloto para entender todo os mecanismos de elaboração e aplicação de normas dentro dessa nova possibilidade, estabelecendo referências para uso futuro.

Para garantir que o uso de tecnologia no cenário legislativo e executivo promova o bem-estar, a interação entre inovação e crescimento econômico deve ser analisada cuidadosamente do ponto de vista do risco e benefícios.

Em outras palavras, é necessário questionar se o uso da IA, para efetivar direitos, supera seus potenciais efeitos negativos no processo de criação de inovações orientadas a dados.

\section{REFERÊNCIAS}

BARROSO, Luis Roberto. Curso de direito constitucional contemporâneo: os conceitos fundamentais e a construção do novo modelo. 3. ed. São Paulo: Saraiva, 2011.

BIONI, Bruno Ricardo. Proteção de Dados Pessoais: a função e os limites do consentimento. Rio de Janeiro: Forense, 2018.

BURK, Dan L. Algorithmic Fair Use. University of Chicago Law Review. 2018. Disponível em: <https://lawreview.uchicago.edu/publication/algorithmic-fair-use $>$. Acesso em: 01 de abril de 2020.

CASSI, Guilherme H. Galino. A eficiência segundo a análise econômica do direito. Hermenêutica. Curitiba, 2013. Disponível em: $<$ http://www.publicadireito.com.br/publicacao/unicuritiba/livro.php?gt=93>. Acesso em: 01 de abril de 2020.

CASEY; Anthony J.; NIBLETT, Anthony. A Framework for the New Personalization of 
Law. University of Chicago Law Review. 2019. Disponível em: $<$ https://lawreview.uchicago.edu/publication/framework-new-personalization-law $>$. Acesso em: 01 de abril de 2020 .

CAVALCANTI, Francisco Ivo Dantas. TEORIA DA RECEPÇÃO LEGISLATIVA E OS SISTEMAS CONSTITUCIONAIS. Revista Juridica, [S.1.], v. 1, n. 46, p. 355-384, jul. 2017. ISSN 2316-753X. Disponível em: <http://revista.unicuritiba.edu.br/index.php/RevJur/article/view/2012/1293>. Acesso em: 18 abr. 2020. doi:http://dx.doi.org/10.21902/revistajur.2316-753X.v1i46.2012.

CORVALÁN, Juan Gustavo. Inteligência Artificial y Derechos Humanos (parte I). 2017. Disponível em: <http://dpicuantico.com/area_diario/doctrina-en-dos-paginas-diarioconstitucional-y-derechos-humanos-nro-156-03-07-2017/>. Acesso em: 29 março de 2020.

CORVALÁN, Juan Gustavo. Inteligência Artificial y Derechos Humanos (parte II). 2017. Disponível em: <https://dpicuantico.com/sitio/wp-content/uploads/2017/07/Juan-GustavoCorvalan-Constitucional-10.07.2017.pdf>. Acesso em: 29 março de 2020.

Dados Estruturados e Não Estruturados. Blog, Tecnologia da Informação. Universidade da Tecnologia. Disponível em: < https://universidadedatecnologia.com.br/dados-estruturadose-nao-estruturados/>. Acesso em: 29 março de 2020.

ELKIN-KOREN, Niva. GAL, MICHAL S. The Chilling Effect of Governance-by-Data on Data Markets. University of Chicago Law Review, 2018. Disponível em: < https://lawreview.uchicago.edu/publication/chilling-effect-governance-data-data-markets>. Acesso em: 29 março de 2020.

ERL, Thomas; KHATTAK, Wajid; BUHLER, Paul. Big Data Fundamentals: Concepts, Drivers \& Techniques. Boston: Prentice Hall, 2016.

FEIGELSON, Bruno; e SIQUEIRA, Antonio Henrique Albani. Comentários à Lei Geral de 
Proteção de Dados. São Paulo: Thomson Reuters Brasil, 2019.

GILLIS, Talia B.; e SPIESS. Jann L. Big Data and Discrimination. University of Chicago Law Review, 2018. Disponível em: <https://lawreview.uchicago.edu/publication/big-data-anddiscrimination>. Acesso em: 29 março de 2020.

GRAF, Simonne Cristine; COSTA, Eder Dion de Paula. Os desafios e perspectivas do estado no cumprimento do dever de prestação de serviços de saúde. Revista Juridica, [S.1.], v. 2, n. 35, p. 75-87, nov. 2014. ISSN 2316-753X. Disponível em: 〈http://revista.unicuritiba.edu.br/index.php/RevJur/article/view/939/644>. Acesso em: 14 abr. 2020. doi: http://dx.doi.org/10.21902/revistajur.2316-753X.v2i35.939.

LÓSCIO, Bernadete Farias; OLIVEIRA, Hélio Rodrigues; e PONTES, Jonas César de Souza. NoSQL no desenvolvimento de aplicações Web colaborativas, 2011. Disponível em: $<$ https://www.addlabs.uff.br/sbsc_site/SBSC2011_NoSQL.pdf $>$. Acesso em: 29 março de 2020.

LOPES, José Reinaldo de Lima. Raciocínio jurídico e economia. Faculdade de Direito da USP. Disponível em: $<$ https://edisciplinas.usp.br/pluginfile.php/4110089/mod_resource/content/1/Lima\%20Lopes\%2 C\%20Jos\%C3\%A9\%20Reinaldo.\%20Racioc\%C3\%ADnio\%20jur\%C3\%ADdico\%20e\%20econ omia.pdf >. Acesso em: 29 março de 2020.

MANYIKA, James; CHUI, Michael; e BROWN, Brad; et al. Big data: The next frontier for innovation, competition, and productivity. McKinsey Global Institute, 2011. Disponível em: < https://www.mckinsey.com/ /media/McKinsey/Business\%20Functions/McKinsey\%20Digital/ Our\%20Insights/Big\%20data\%20The\%20next\%20frontier\%20for\%20innovation/MGI_big_dat a_exec_summary.ashx>. Acesso em: 29 março de 2020.

POSNER, Richard. As fronteiras do direito. São Paulo: Martins Fontes, 2010. 
POZZEBON, Eliane; FRIGO, Luciana Bolan; e BITTENCOURT, Guilherme. Inteligência artificial na educação universitária: quais as contribuições? Campinas: Revista CCEI 8 (13), p. 34-41, 2004.

Preparing for the Future of Artificial Inteligence. Executive Office of the President National Science and Technology Council Committee on Technology. 2016. Disponível em: $<$ https://obamawhitehouse.archives.gov/sites/default/files/whitehouse_files/microsites/ostp/NST C/preparing_for_the_future_of_ai.pdf $>$. Acesso em: 29 março de 2020.

RUSSEL, Stuart J.; e NORVIG, Peter. Inteligência Artificial. 2. ed. Rio de Janeiro: Campus, 2004.

TECHAMERICA. TechAmerica Foundation Federal Big Data Commision. Demystifying big data: A Practical Guide to Transforming The Business of Government, 2012. Disponível em:<https://bigdatawg.nist.gov/_uploadfiles/M0068_v1_3903747095.pdf $>$. Acesso em: 29 março de 2020.

VIANNA, William Barbosa; DUTRA, Moisés Lima; e FRAZZON, Enzo Morosini. Big data e gestão da informação: modelagem do contexto decisional apoiado pela sistemografia. Informação \& Informação, v. 21, n. 1, 2016, p. 185. Disponível em: $<$ http://www.uel.br/revistas/uel/index.php/informacao/article/view/23327/18993>. Acesso em: 29 março de 2020.

VERSTEIN, Andrew. Privatizing Personalized Law. University of Chicago Law Review. 2019 2019. Disponível em: <https://lawreview.uchicago.edu/publication/privatizing-personalizedlaw>.

WEF. World Economic Forum. Big Data, Big Impact: New Possibilities for International Development, 2012. Disponível em: < http://www3.weforum.org/docs/WEF_TC_MFS_BigDataBigImpact_Briefing_2012.pdf>. 
Acesso em: 29 março de 2020. 